\title{
Establishment of the Concept of Lifetime Sports Based on College Competitive Sports Training
}

\author{
Song Ye \\ University of Electronic Science and Technology of China, Chengdu, 610054, China
}

Keywords: College sports, Competitive sports, Lifetime Sports concept

\begin{abstract}
Sports can enhance the body's physique, exercise the will of the people, and is popular by the people all over the world, and competitive sports activities will stimulate people's ambition. In particular, the Olympic Games, which take competitive sports as the main content, have attracted the attention of the people all over the world. Under the influence of the wrong idea of "high reading", the position of competitive sports is not high, and the universities do not attach much importance to the sports of students. Until 1987, the State Board of Education and the State Sports Commission issued On the Amateur Sports Training School to Improve the Level of Sports Planning to begin to carry out the school sports teaching.
\end{abstract}

\section{Introduction}

Competitive sports is an important part of human movement culture. Its greatest charm lies in its ability to maximize the potential of individuals or collectives in terms of mind and body. The attraction of competitive sports to young people is great. But sports may cause injuries to the athletes, so the school should strengthen the training of competitive sports. However, there are still many problems in China's efficient sports teaching, such as improper management. Lifelong sports is the extension of competitive sports, which is the guarantee for a person to be based on the foundation of physical quality in society. This paper discusses the problems of physical education in colleges and universities, and puts forward the measures to cultivate the students' lifelong physical education.

\section{Concept of Lifetime Sports}

\subsection{Meaning of Lifetime Sports}

Lifelong physical education is a person with a lifelong physical exercise of physical attitude and physical ability as well as lifelong physical exercise. The lifelong sports and the core are the whole life of sports. Lifelong physical education has two meanings: one refers to the idea of lifelong sports under the guidance of the sport system integrated as the goal, to provide practice opportunities to participate in sports activities in different periods and different areas of life; two is a person's life in sports, lifelong learning and exercise, make sports become an integral part of life.

\subsection{Development Background of Lifetime Sports}

"Lifelong sports" is a new sports thought put forward by the former Soviet Union scholars. In 1960s, the famous educationist Paul Lengrand put forward the idea and theory of lifelong education in the introduction of lifelong education. In 1987, the State Board of education, the State Sports Commission issued "on the amateur sports training school, to improve the level of sports planning" files, physical education into the education system of our country. After more than ten years' development, whether in the field of education or in the social field, the concept of lifelong physical education has had a profound and significant impact on the scientific research and practice of physical education, and it has an irreplaceable position and role in college physical education. 


\subsection{Practical Significance of Lifetime Sports}

Lifelong physical education is the prerequisite for the realization of the ideal of "learning society". With the continuous development of the social economy and the continuous progress of science and technology, the rhythm of the society is accelerating, including work, learning and even life. The accelerated pace of life forces people to put forward higher demands on their own physical qualities. Strong physique has become a solid foundation for people to adapt to social development. Due to the characteristics of tightness and systematisms in lifelong sports, the importance of it in the education system is increasing day by day. It has become an essential part of realizing "learning society".

Lifelong physical education is an urgent need to solve the problem of modern "civilization disease". Because of the rapid development of modern society, in order not to be abandoned by the times, people are forced to spend more time and energy on their work and study. Modern people are more or less likely to have some physical and psychological problems, such as lumbar disc herniation, cervical spondylosis, depression, and so on. Lifelong physical exercise is the best way to prevent and treat modern "civilized diseases". Therefore, to a certain extent, the lifelong sports practice of the whole society has become one of the urgent needs of the harmonious development of human society.

Lifelong physical education is a modern life style to improve the people's quality of life and pursue a healthy and long life. The pace of modern society is too fast. In order to adapt to the development of society, people spend most of their time and energy on work and study. In order not to be abandoned by the times, modern people spend too much time on their work, and they have no time to use them in sports. Therefore, most modern people lack of exercise, the physical quality is not high, the life of their own will be affected. Lifelong physical exercise is an important symbol of modern life style. It reflects people's pursuit and practice of modern life style. Its goal is to take sport as a part of life and enjoy it for life.

\section{Necessity of Development of Lifetime Sports in College Sports}

Sports can enhance the body, exercise the will of the people, but also enhance the human resistance, so that it is free from the disease. Therefore, it is necessary to cultivate the people's lifelong physical education consciousness. In 1987, China took physical education as a compulsory course for the national schools. Until now, China's physical education has been developed for several decades. However, because of the great environmental impact on the study and the attitude of the parents, the school has not paid enough attention to sports, especially in colleges and universities. Until now, the physical education classes in most colleges and universities are lower than the state regulations. The following is a specific analysis of the status of sports education in China.

\subsection{Necessity of Development of Lifetime Sports}

It is the requirement of social development to cultivate the consciousness of lifelong physical education. The competition of modern society is the competition of social resources, including the competition of talent and money. The need for talent is urgent in society. But if you don't have a healthy body, you can't find Bole even if you have a good talent. In order to adapt to the rapid change of the society, the modern society has put forward higher requirements for the physical quality of the talents in order to adapt to the rapid change of the society. In this competitive social environment, only healthy bodies are the basis for development and progress.

To cultivate the consciousness of lifelong physical education is the need of social development. College education is the transition stage of contemporary college students from students to social people. It is the initial stage of the students from the ivory tower to the society. To cultivate students' lifelong physical awareness can improve their physical quality and deliver better qualified talents for the society.

\subsection{Current Situation of College Sports Education}

The setting of school teaching is not reasonable. Most of the current college physical education 
attaches great importance to students' life safety. The teaching contents are mainly related to the theoretical knowledge of sports activities and the practice of basic sports activities. At the same time, the way of physical examination is unreasonable. The school attaches too much importance to the examination of sports theoretical knowledge and ignores the assessment of students' sports skills. In this way, the teaching method that emphasizes the basic theory makes the students lack the feeling of life-long benefit, and cannot cultivate the students' lifelong physical education consciousness. When the students' learning career ends, the general students' physical exercise process is finished.

The teaching method is backward and the form of teaching is monotonous. In the present college physical education, the teaching methods of teachers are generally limited to sports teaching materials, mainly explaining and demonstrating, repeating exercises and competitions. For some new teaching methods, such as situational teaching, game teaching, and so on, it is still not used by most teachers in the teaching practice. At the same time, the sports course of modern colleges and universities is short, and the interval of each class is too long. In the course of teaching, students often cannot remember the content of the previous study, and need teachers to re teach, leading to repeated teaching. Finally, the students have only mastered the basic sports skills in the whole term of physical education. And these basic sports technology cannot meet the students' pursuit of modern sports culture.

Students lack enthusiasm for physical exercise. The lifelong sports consciousness of the contemporary college students is weakening, and it is impossible to realize the close relationship between the importance of physical exercise and the importance of the future development. After entering the university campus, the students' interest in all aspects has been fully developed, and there is not enough time to carry out sports activities. At the same time, because the students physical quality in the full vigor of life cannot find the importance of physical exercise. Moreover, contemporary college students are under the dual pressure of learning and society, not only to enhance their professional knowledge, but also to participate in various practical activities in their spare time.

\section{Measures of Concept Cultivation of Lifetime Sports}

\subsection{Strengthen the Consciousness of Lifetime Sports}

According to the survey, some students in school, especially girls, lack knowledge of sports, have little understanding of sports, and lack interest in physical exercise, let alone participate in sports activities consciously. Therefore, the school physical education is to strengthen the cultivation of the students' lifelong physical education consciousness. Increase the class hour of ideological education, explain the modern social situation for students, let students understand the importance of sports, so that students can actively exercise.

\subsection{Strengthen Theoretical Knowledge Teaching related with Sports}

When carrying out sports activities, adequate theoretical knowledge is the safety guarantee for sports activities. If we want to cultivate students' lifelong sports consciousness, we must teach students enough theoretical knowledge. When the school management arranges the teaching process of physical education, it is necessary to scientifically plan the theoretical knowledge of sports and the hours of sports practice.

In carrying out sports theory knowledge teaching, teachers should make sure that students clearly know the purpose, task and importance of participating in physical exercise, and impart scientific methods of physical exercise, organization and arrangement of sports activities, and specific rules of various sports competitions to students. At the same time, teachers should teach students how to protect themselves in sports activities, how to do basic treatment and how to exercise related health knowledge when they are injured. In this way, we can make the students exercise scientifically so as to change the students' understanding of sports. In addition, the increase of health knowledge physical education is also conducive to the cultivation of students' lifelong physical awareness. 


\subsection{Improve Teaching Methods}

In the past, the teaching of instillation in physical education has only paid attention to the teaching of theoretical knowledge of students, and few of them have the opportunity to carry out sports practice. Lack of interest in theoretical knowledge and lack of spirit in physical education can make students unable to develop their habit of participating in sports activities independently, let alone training their ability to organize sports activities.

Teachers can try new teaching methods, such as game teaching, to arouse students' enthusiasm and improve students' interest in physical exercise. For example, setting up various small competitions according to the students' preferences, bringing up students' interest in sports and cultivating students' awareness of participation. The competition of teachers cannot be too big, so we need to create opportunities for students to create more opportunities, so that students can fully express their abilities in sports and make students from passive exercise to active exercise.

\subsection{Set up Special Elective Courses}

The college can set up special physical education courses to help students to choose the sports activities that want to learn, and greatly improve the enthusiasm of the students' sports activities. At the same time also allows students to systematically study the special movement of knowledge and technology, not only on the basis of the sports knowledge and technology have more understanding and grasp, but also the basic theory of gradually understanding and awareness of the special sports activities and other special sports learning, it is easy to extrapolate from one. With the continuous learning activities and the continuous enrichment and improvement of knowledge and technology, the cognition of learning will create a new leap, and then form a conscious physical consciousness, good sports ability and habits, and become indissoluble with sports and become a lifelong sports person in the future.

\subsection{Enhance Student's Competence of Participating in Physical Exercise Independently}

Ability comes from practice. To cultivate students' ability in physical education, it is necessary to give students the opportunity to practice more. Teachers on the teaching content to update teaching methods should be innovative, bold to let students organize their own regular content classes, such as in the preparation part and relaxation activities, play the initiative of students, let students organize some activities under the guidance of teachers, so as to develop students' personality, and culture students bold command ability, stimulate their learning enthusiasm. In extracurricular sports activities, we should actively guide and encourage students to organize their own competitions, serve as referees themselves, and manage themselves in various activities, so that they can master the scientific methods of self-exercise and the ability to participate in physical exercise independently.

\section{Conclusions}

With the increasing attention of the state to sports, the physical education in our country is in a rare opportunity for development. Under the guidance of relevant policies and under the guidance of Scientific Outlook on Development, our universities should step out of the sports development path with Chinese characteristics and cultivate excellent reserve talents for our sports industry. College students can use as teenagers strong ambition, curiosity about the world, to improve the students' enthusiasm in sports activities, stimulate students' love for sports activities, to cultivate students lifelong sports consciousness to promote students' life more beautiful.

\section{References}

[1] Yu Jiying, Song Quanzheng, Yang Zaihuai, et al. Countermoves for Sustainable Training of Competitive Sports Talent under System of “Opening Grand Education” [J]. Journal of Shanghai University of Sport, 2006, 30(6): 29-35. 
[2] Yuan Hao, Liu Cheng, Liu Lanjuan. On the Training Mechanism of Excellent College Athletes in Chinese Colleges and Universities of the New Period [J]. SportForum, 7(4): 27-30.

[3] Xu Qiuhong. Enlightenment Regarding to Colleges and Universities' High-level Competitive Sports Development in the United States [J]. Journal of Nanjing Sport Institute (Natural Science), 2014, 13(1): 51-55.

[4] Bin Jinsheng, Zhang Chunhe. A Study on the Need and Supply of Competitive Sports System of College in the New Context [J]. Journal of Beijing Sport University, 2010, 33(11): 91-93+97. 